\title{
The Effect of Social Media/Smartphone Addiction and Sleep Quality on Academic Success in Medical Faculty Students
}

\author{
Tıp Fakültesi Öğrencilerinde Sosyal Medya/Akıllı Telefon \\ Bağımlılığı ve Uyku Kalitesinin Akademik Başarı üzerine \\ Etkisi
}

Sakir Gica ${ }^{1}$,

Sena Yunden ${ }^{1}$

Aysegul Kirkas ${ }^{1}$,

Fatma Sevil ${ }^{1}$

Faik Ozdengul'2,

Mehmet $\mathrm{Ak}^{1}$

${ }^{1}$ Necmettin Erbakan University, Meram Faculty of Medicine, Department of Psychiatry, Konya, Turkey

${ }^{2}$ Necmettin Erbakan University, Meram Faculty of Medicine, Department of

Physiology, Konya, Turkey

Geliş Tarihi/Received: 19 July 2020

Kabul Tarihi/Accepted: 18 August 2020

Address correspondence to: Sakir Gica, Necmettin Erbakan University, Meram Faculty of Medicine, Department of Psychiatry, Konya, Turkey

e-mail: sgica@erbakan.edu.tr

ORCID

Sakir Gica

https://orcid.org/0000-0001-7387-8840

Sena Yunden

https://orcid.org/0000-0001-9749-3945

Aysegul Kirkas

https://orcid.org/0000-0001-7846-9915

Fatma Sevil

https://orcid.org/0000-0002-0199-7565

Faik Ozdengul

https://orcid.org/0000-0001-9670-0789

Mehmet Ak

https://orcid.org/0000-0003-1771-5654

\begin{abstract}
Öz
Amaç: Çalışmamızın amacı klinik öncesi tıp eğitimi alan öğrencilerde akıllı telefon / sosyal medya kullanımı ve uyku ile ilgili değişkenlerin akademik başarı üzerine etkisini değerlendirmektir.

Gereçler ve Yöntem: Çalışmaya aynı kurumda klinik öncesi tıp eğitimi alan 226 öğrenci dahil edilmiştir. Tüm katılımcılar Pittsburg Uyku Kalitesi Indeksi (PUKi), Sosyal Medya Bağımlılığı Öıçeği - Yetişkin Formu (SMBÖ-YF), Akıllı-telefon Bağımlılığı Ölçeği (ATBÖ) doldurmuştur.

Bulgular: Akıllı telefon bağımlılığı risk durumuna göre bağımlılık riski düşük olan grubun not ortalaması $71.8 \pm 8$ iken, bağımlılık riski orta olan grubun $68.4 \pm 8.77$ ve yüksek olan grubun ise $67.4 \pm 9.75$ idi. Akıllı telefon bağımlıı̆ı̆ı açısından düşük riskli grubun not ortalamaları yüksek riskli grubun not ortalamalarından anlamlı bir şekilde yüksekti. Akıllı telefon bağımlılığı açısından yüksek riskli grubun sosyal medya bağımlılık toplam skorları orta ve düşük riskli gruptan anlamlı bir şekilde yüksekti. Oluşturulan multivariate Hiyerarşik Regresyon Analizi modelinde cinsiyet, uyku etkinliği, ATBÖ ve SMBÖ-YF skorlarının not ortalamaları üzerinde etkili olduğu saptandı.

Sonuç: Sonuç olarak çalışmamızın sonuçları tıp öğrencilerinin klinik öncesindeki eğitim dönemlerinde sosyal medya / akılı telefon kullanımlarının ve uyku alışkanlıklarının akademik başarı üzerine etkili olduğunu desteklemektedir. Bilinçli sosyal medya ve akıllı telefon kullanımıyla ilgili eğitimler planlanması ve uyku alışkanlığının öneminin vurgulanması tıp eğitiminde daha donanımlı hekimlerin yetiştirilebilmesine katkı sağlayabilecek potansiyele sahiptir.
\end{abstract}

Anahtar Kelimeler: Akademik başarı, sosyal medya, akıllı telefon, bağımlılık, uyku

\section{Abstract}

Aim: The aim of this study was to evaluate the effects of smartphone / social media use and sleep related variables on academic achievement in pre-clinical medical students.

Materials and Methods: 226 students receiving pre-clinical medical education at the same institution were included in the study. All participants completed the Pittsburg Sleep Quality Index(PSQI), Social Media Addiction Scale - Adult Form(SMAS-AF), Smartphone Addiction Scale(SAS). The participants were categorized as low / medium / high risk according to the scores of smartphone addiction scale.

Results: According to the risk of smartphone addiction, the mean score of Average Acamedic Marks(AAM) of the group with low dependency risk was $71.8 \pm 8$, the mean score of AAM of the group with the middle risk dependency risk was $68.4 \pm 8.77$, and the mean score of AAM of the group with the high dependency risk was $67.4 \pm 9.75$. The mean scores of AAM of the low-risk group in terms of smartphone addiction were significantly higher than the high-risk group. Social media addiction total scores of the high risk group in terms of smartphone addiction were significantly higher than the medium and low risk group. A multivariate hierarchical regression analysis model suggested that gender, sleep efficiency, SAS and SMASAF scores affected AAM.

Conclusion: Use of social media/smartphone by medical students can affect sleep habits and academic success during the period of pre-clinical education. Inclusion of training on conscious use of social media and smartphone and emphasizing the importance of sleep habits in medical education have the potential to contribute to the development of better-equipped physicians.

Key words: Academic success, social media, smartphone, addiction, sleep
Cite this article as: Gica S, Yunden S, Kirkas A, Sevil F, Ozdengul F, Ak M. The Effect of Social Media / Smartphone Addiction and Sleep Quality on Academic Success: A Retrospective Study in Pre-Clinic Medical Faculty Students. Selcuk Med J 2020;36(4): 312-318 Disclosure: None of the authors has a financial interest in any of the
products, devices, or drugs mentioned in this article. The research was
not sponsored by an outside organization. All authors have agreed to allow
full access to the primary data and to allow the journal to review the data
if requested. 


\section{INTRODUCTION}

Medical school education has a very broad curriculum even when solely the content of theoretical knowledge is evaluated. Therefore, due to the high stress factor in medical education, students have increased symptoms of depression and anxiety compared to their peers in the general population (1, 2 ) and students in other faculties $(3,4)$. In addition to psychiatric disorders such as depression, anxiety and sleep disorders, there are many physical, social, environmental, financial and other factors that can affect academic success in students.

With the development of technology in the past 20 years, internet, smartphone and social media usage have become an important part of daily life. The widespread use of smartphones with the ease of providing internet access at any time in many areas such as business, education, entertainment, communication, and trade has brought along concerns about the potential for problematic use and addiction in individuals (5). It has been found that individuals experience separation anxiety (6) and show symptoms similar to withdrawal symptoms (7) when they stay away from these technological tools. The American Psychiatric Association (APA) included substance use-related behavioral addictions in its diagnostic system in 2013 for the first time and identified Gambling Disorder as a behavioral addiction. However, it was emphasized that Internet Game Playing Disorder should be investigated for its potential as a behavioral addiction $(5,8)$. Recent studies indicate that smartphone use and social media addiction are on the rise and cause many negative effects, both physically and spiritually (5, 9-16). In the literature, the role of factors such as poor sleep quality (17), excessive stress (18), social media addiction (19), internet addiction (20) and smartphone addiction (21) on academic achievement and academic success of students have been widely investigated. However, the findings cannot be replicated in every study, and contradictory findings have been reported.

Our aims in this study were the following: i. to investigate the use of smartphone and social media among medical school students, ii. an in-depth evaluation of the effects of smartphone use on academic success, and iii. to evaluate the factors related to addiction and sleep that can affect academic success in a holistic way. We think that the findings of our study can contribute to the improvement of academic success by determining factors that can negatively affect the education process in medical school students as well as other students of a similar age.

\section{MATERIALS AND METHODS Participants}

The study sample was composed of 226 medical students. Thirteen participants were excluded from the study as they had a psychiatric disease or used psychotropic drugs. One-hundred and thirty six participants $(63.8 \%)$ were female, and seventy seven $(36.2 \%)$ were male. The age of the participants ranged from 18 to 25 years. The criteria for recruitment included age of 18 years and above and voluntary participation. The study protocol was approved by Research Institute's committee on human research (IRB Date/Number: 06.06.2020/2020-2586).

\section{Data Collection Tools \\ Personal Information Form}

A personal information form was created to obtain demographic information about the participants. The form included questions about age, gender, education level and psychiatric diagnoses.

\section{Pittsburg Sleep Quality Index (PSQI)}

The PSQI was developed by Buysse et al. (1989) (22) and was adapted to Turkish by Ağargün et al. (1996) (23). PSQI is a 19-item self-report scale that evaluates sleep quality and sleep disorder in the past month. It consists of 24 questions; 19 questions are self-report questions while 5 questions are answered by a spouse or roommate. The scored 18 questions consist of 7 components that include Subjective Sleep Quality, Sleep Latency, Sleep Time, Conventional Sleep Efficacy, Sleep Disorder, Sleep Drug Use and Daytime Dysfunction. Each component is evaluated with a score of 0-3 points. The combined scores of the 7 components gives the total score of the scale. The total score ranges from 0-21. A total score greater than 5 indicates "poor sleep quality".

\section{Social Media Addiction Scale - Adult Form (SMAS-} AF)

This scale was developed by Şahin and Yağcı in 2017 (24). The SMDS-YF has a 5 Likert type structure consisting of 2 sub-dimensions (virtual tolerance and virtual communication) and 20 descriptions. The virtual tolerance sub-dimension consists of items $1-11$, and virtual communication consists of items 1220. Items 5 and 11 are reversed. The highest score that can be obtained from the scale is 100 , and the lowest score is 20. A high score is evaluated as the perception of an individual as a "social media addict". Smartphone Addiction Scale (SAS) 
Smartphone Addiction Scale (SAS) was developed by Kwon et al. and is based on Young's scale of internet addiction and features of smartphones (25). In this scale, the options are between 1 (absolutely not) and 6 (definitely yes). High scores indicate a higher risk of smartphone addiction. The total score of the scale can range from 33 to 198. No breakpoint was reported on the original scale. The validity and reliability analysis of SAS provided a six-factor structure. The subscales were defined as daily life disorder, positive reinforcement, abstinence, relation to cyber space, overuse and tolerance. The Turkish validity and reliability study was performed by Demirci et al. in 2014 (26).

\section{Procedure}

Aquestionnaire was provided to the students within the scope of the "Fight Against Addiction" course in the framework of pre-clinical 2020 spring education program of the Psychiatry Department at our institution. The aim of the questionnaire was to raise awareness about social media use and smartphone addiction. The forms were evaluated retrospectively and the data were analyzed in June, 2020.

\section{Statistical Analysis}

Statistical Package for the Social Sciences (SPSS) 16.0 software package for Windows (SPSS Inc., Chicago, IL, USA) was used for statistical analyses. Descriptive statistical methods (frequency, percentage, mean, and standard deviation) were used for evaluating the study data. The variables were examined to determine whether they were appropriate for normal distribution using visual (histogram and probability diagrams) and analytical (Kolmogorov-Smirnov and Shapiro-Wilk) tests. The total scores of Smartphone Addiction Scale (SAS) were divided into 3 categories as low, medium and high risk in terms of smartphone addiction by using visual binning. Chi-square and Fisher's exact test were used to compare qualitative data. One-Way ANOVA was used to compare normally distributed numerical variables between independent groups. Relationship analysis between numerical variables were evaluated by Pearson correlation test. Finally, hierarchical multivariate linear regression analysis was used to examine the factors affecting the Average Acamedic Marks (AAM) of students. $p<0.05$ was accepted as the level for statistical significance.

\section{RESULTS}

The average age of the participants included in the study was $20.07 \pm 1.25$ years, and the AAM was 71.1 \pm 8.85 (min-max:40-95). No significant difference was observed between participants in the comparison of age, gender and level of education of the parents of the participants to the risk of smartphone addiction. The comparison of the socio-demographic data of the participants according to the status of their smartphone addiction risk is shown in Table 1. When the AAM, sleep times, bedtime, PSQI total scores and social media addiction scores of the participants were compared according to the risk of smartphone addiction, a statistically significant difference was detected in the AAM and social media addiction scores between the low risk group and the high risk groups $(p=0.035$ and $p<0.001$, respectively); however, there was no difference in the sleep-related data. Data on the comparison of the AAM, sleep times, bedtime, PUKI total scores and social media addiction scores between the groups are shown in Table 2.

When the factors associated with AAM were analyzed by Pearson correlation analysis, a statistically significant positive relationship was detected between AAM and sleep efficiency $(r=0.19$, $p<0.001)$ while a significant negative correlation

Table 1. Comparison of Participants' Sociodemographic Data According to the Risk Status of Smartphone Addiction

\begin{tabular}{|c|c|c|c|c|c|}
\hline & Group 1 & Group 2 & Group 3 & F/df & $p$ \\
\hline Age & $19.8 \pm 1.20$ & $20.16 \pm 1.22$ & $20.07 \pm 1.23$ & 1.37 & 0.271 \\
\hline \multirow[t]{2}{*}{ Gender(\%) } & Male:23(41.8\%) & Male: $19(34.5 \%)$ & Male:23(43.4\%) & 2 & 0.603 \\
\hline & Female:32(58.2\%) & Female:36(65.5\%) & Female:30(56.6\%) & & \\
\hline \multirow[t]{4}{*}{ Mother Education Level (\%) } & Primary & Primary & Primary & 2 & 0.055 \\
\hline & School:26(47.3\%) & School:14(25.5\%) & School:18(34.0\%) & & \\
\hline & Middle School And & Middle School And & Middle School And & & \\
\hline & Upper:29(52.7\%) & Upper:41(74.5\%) & Upper:35(66\%) & & \\
\hline \multirow[t]{4}{*}{ Father Education Level (\%) } & Primary & Primary & Primary & 2 & 0.912 \\
\hline & School:6(10.9\%) & School:6(10.9\%) & School:7(13.2\%) & & \\
\hline & Middle School And & Middle School And & Middle School And & & \\
\hline & Upper:49(89.1\%) & Upper:49(89.6\%) & Upper:46(86.8\%) & & \\
\hline
\end{tabular}

Group 1:Low Risk of Smartphone Addiction Scale, Group2: Middle Risk of Smartphone Addiction Scale, Group3: Upper Risk of Smartphone Addiction Scale

One way Anova Test and Chi-Square test were performed. 
Table 2. Comparison of PSQI, Social Media Addiction and Average Academic Marks of Participants According to Smartphone Adduction Scale Risk Status

\begin{tabular}{|c|c|c|c|c|c|}
\hline & Group 1 & Group 2 & Group 3 & f & p \\
\hline Average Academic Marks & $71.8 \pm 8$ & $68.4 \pm 8.77$ & $67.4 \pm 9.75^{a}$ & 3.417 & $0.035^{*}$ \\
\hline SMASAF-VT & $23.21 \pm 7.05$ & $30.16 \pm 5.22^{a}$ & $29.4 \pm 8.1^{\mathrm{ab}}$ & 46.40 & $<0.001$ \\
\hline SMASAF-VC & $17.03 \pm 4.93$ & $21.7 \pm 5.23^{a}$ & $21.3 \pm 6.4^{\mathrm{ab}}$ & 32.61 & $<0.001$ \\
\hline SMASAF-TOT & $40.4 \pm 11.17$ & $51.7 \pm 9.2^{\mathrm{a}}$ & $50.8 \pm 12.9^{a b}$ & 56.71 & $<0.001$ \\
\hline Sleep Duratıon & $55 \pm 6.88$ & $55 \pm 6.88$ & $53 \pm 6.85$ & 0.011 & $0.989^{*}$ \\
\hline PSQI Total & 55 & 55 & 52 & 0.483 & $0.818^{*}$ \\
\hline
\end{tabular}

Group 1: Low Risk of Smartphone Addiction Scale, Group2: Middle Risk of Smartphone Addiction Scale, Group3: Upper Risk of Smartphone Addiction Scale, SMASAF: Social Media Addiction Scale - Adult Form, VT: Virtual Tolerance, VC: Virtual Communication, TOT: Total Score, PSQI: Pittsburg Sleep Quality Index

One way Anova Test was performed. For One-Way Anova test, homogeneity was checked with Levene Statistic test and Tukey HSD test was applied if it showed homogeneous distribution according to homogeneity status

a $p<0.05$ (Compared with group 1)

b $p<0.05$ (Compared with group 2)

was observed between AAM the total SAS score and hours spent in bed $(r=-23, p<0.001 ; r=-27, p$ $<0.05$, respectively). A positive, statistically significant and strong correlation was found between the total SAS score and SMASAF score $(r=0.73, p<0.001)$. No significant relationship was detected between the PSQI scores and SAS total or any sub-dimension scores. A positive correlation was detected between AAM and SMASAF VT and total scores $(r=0.23$, $p<0.001 ; r=0.17, p<0.05$, respectively). The relationships between the variables used in the study are shown in Table 3.

A multivariate hierarchical regression analysis was used to examine the factors affecting the AAM of the participants included in our study. In this modeling, it was found that gender, sleep efficiency, SAS and SMASAF scores were effective on the AAM. Results of the hierarchical regression analysis on the AAM are shown in Table 4.

\section{DISCUSSION}

Our study was designed to examine the effects of social media and smartphone use / addiction and sleep-related factors (efficacy, duration of sleep, time spent in bed and quality of sleep) on academic achievement levels in students receiving pre-clinical medical education. Another aim of this study was to examine the relationship between smartphone / social media use and sleep related factors. The use of smart phones was found to negatively affect academic

Table 3. Examining the Correlation between Quality of Sleep, Smartphone / Social Media Addiction and Academic Success.

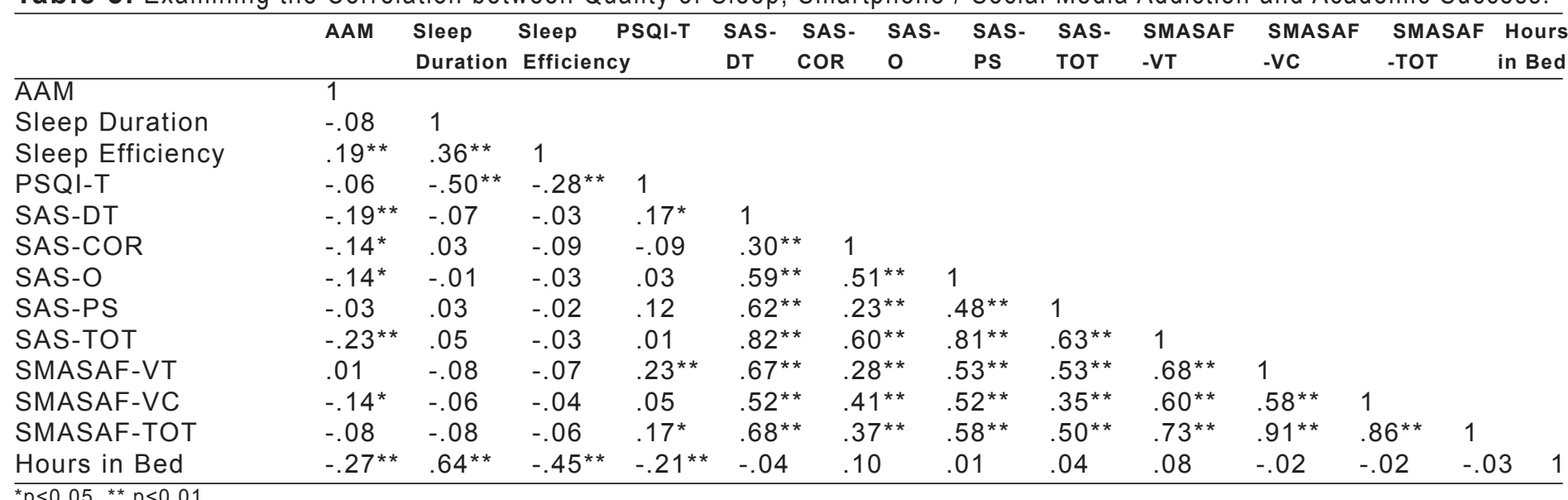

AAM: Average Academic Marks, PSQI-T: Pittsburg Sleep Quality Index Total, SAS: Smartphone Addiction Scale, DT: Disturbing daily life and Tolerance, COR: Cyberspace-Oriented Relationships, O: Overuse, PS: Physical Symptoms, SMASAF: Social Media Addiction Scale - Adult Form , VT: Virtual Tolerance,

VC: Virtual Communication, TOT: Total Score. 
Table 4. Results of Hierarchical Regression Analysis Regarding The Average Acamedic Marks

\begin{tabular}{|c|c|c|c|c|c|}
\hline & $\beta$ & $\mathbf{t}$ & $\mathbf{R}^{2}$ & $\mathbf{F}$ & $F_{\text {change }}$ \\
\hline Step I & & & .091 & $4.901^{* *}$ & 4.901 \\
\hline Gender & .21 & $2.57^{*}$ & & & \\
\hline Sleep Duration & -.16 & -1.768 & & & \\
\hline Sleep Efficiency & .20 & $2.184^{*}$ & & & \\
\hline Step II & & & .185 & $6.518^{* * *}$ & $8.217^{* * *}$ \\
\hline Gender & .26 & $3.363^{* * *}$ & & & \\
\hline Sleep Duration & -.17 & $-1.975^{*}$ & & & \\
\hline Sleep Efficiency & .20 & $2.325^{*}$ & & & \\
\hline SAS-DT & -.25 & $-3.189^{* *}$ & & & \\
\hline SAS-PA & -.16 & $-2.111^{*}$ & & & \\
\hline Step III & & & .266 & $7.362^{* * *}$ & $7.907^{* * *}$ \\
\hline Gender & .24 & $3.202^{* *}$ & & & \\
\hline Sleep Duration & -.16 & -1.931 & & & \\
\hline Sleep Efficiency & .21 & $2.553^{*}$ & & & \\
\hline SAS-DT & -.43 & $-4.135^{\star * *}$ & & & \\
\hline SAS-PA & -.16 & $-2.239^{*}$ & & & \\
\hline SMASAF-VT & .41 & $3.895^{* * *}$ & & & \\
\hline SMASAF-VC & -.19 & $-2.095^{\star}$ & & & \\
\hline
\end{tabular}

Note. ${ }^{*} p<.05,{ }^{* *} p<.01,{ }^{* * *} p<.001$

SAS-DT: , SAS: Smartphone Addiction Scale - Disturbing daily life and Tolerance, SAS-PA: Smartphone Addiction Scale - Positive Anticipation, SMASAFVT: Social Media Addiction Scale - Adult Form -Virtual Tolerance, SMASAF-VC: Social Media Addiction Scale - Adult Form - Virtual Communication

success in the medical students who participated in our study. However, social media use rather than smartphone use was found to be related to sleep quality. In addition, female gender, duration of sleep, and sleep effectiveness were seen to affect academic achievement in medical students. Regardless, some dimensions of smartphone use are likely to affect the academic success of students. Similarly, when social media addiction is considered in general and in its entirety, it was found to be effective on academic success. Social media usage is increasing rapidly with the development of technology. In light of the information reported by the World Internet Statistics Center, it is estimated that there are 3.36 trillion internet users in the world. Increasing social media and smartphone addiction among young people is also an important issue among medical school students. Abu - Snieneh et al. showed that in 2019, medical students who spent more time on social media platforms during the day on an average performed more poorly in their studies (27). Hashmi et al. reported that smartphone use was significantly associated with a lower grade point average in a cohort of 700 students at the King Edward Medical School (28). The findings of the current study confirm the available data in the published literature. In addition, corroborating our data, Al Suwayri et al. reported that the time spent on social media was associated with poor sleep quality (29). In the current study, social media addiction, especially the virtual tolerance subscale, was found to be negatively associated with academic success. In fact, it questions the use of the virtual tolerance sub-dimension as a means of escaping from the real world or redefining life. In this context, since people who use social media spend more time on it and are negatively affected by the lives of others in social media, their academic life may also be negatively affected. On the other hand, it may also mean people who see themselves as unhappy or unsuccessful in real life are more inclined to use social media.

Evaluation of published studies on sleep and academic success indicate a remarkable existence of contradictory results. While some studies have stated that there is no relationship between sleep duration, sleep patterns, sleep activity and academic success $(30,31)$, other studies suggest that sleep disorders indeed affect academic success (32-35), similar to the observations of the current study. The negative effects of sleep-related components or on cognitive functions have long been known. Partial or total sleep deprivation have been shown to adversely affect a wide range of cognitive functions such as attention, processing speed, working memory, and short-term memory (36). Indeed, poor sleep quality and chronic sleep disorders were shown to be associated with poor concentration and attention, with attention being the most sensitive cognitive domain for experimental sleep restriction (36). That sleep disorders affect 
academic success through cognitive functions related to learning is expected. In addition, it is reported that disorders in sleep quality is quite common among students who pursue higher education (37). The prevalence of sleep disorders among medical students and the negative impact of sleep on cognitive functions confirm the practical importance of the results of the current study. In the current study, contrary to our expectations, the correlation between smartphone use and sleep quality did not reach statistical significance. Previous studies indeed have shown that smartphone addiction is associated with poor sleep quality and sleep delay $(21,38)$. In the current study, the scale evaluating the use of the smartphone determined the frequency and intensity of the smartphone use, but did not question the time period during which the usage was intensive. We think that intensive use of smart phones particularly in the evening and at night can affect sleep more negatively. Therefore, we believe that a more detailed assessment is needed.

Our research was carried out in the time period outside the examination period of the education program. Studies that directly target the exam period can help define the relationships more clearly. In this context, this situation may be a limitation of our study. In addition, the period of the day when using smart phones and social media intensifies was not questioned in our study. This is an important issue in illuminating the relationship between smartphone and social media usage and sleep quality. It may be another limitation of our study that this issue is not questioned in our research.

In conclusion, the results of our study support that use of social media / smart phones and sleep habits of medical students could affect their academic success in the pre-clinical education period. Training on the conscious use of social media and smartphones and an emphasis on the importance of good sleep habits in medical education have the potential to contribute to the development of better equipped physicians.

Conflict of interest: Authors declare that there is no conflict of interest between the authors of the article.

Financial conflict of interest: Authors declare that they did not receive any financial support in this study.

Address correspondence to: Sakir Gica, Necmettin Erbakan University, Meram Faculty of Medicine, Department of Psychiatry, Konya, Turkey.

E-mail: sgica@erbakan.edu.tr

Phone number: + 903322236332

\section{REFERENCES}

1. Dahlin ME, Runeson B. Burnout and psychiatric morbidity among medical students entering clinical training: A three year prospective questionnaire and interview-based study. BMC Med Educ 2007;7:6

2. Dyrbye LN, West CP, Satele D, et al. Burnout among U.S. medical students, residents, and early career physicians relative to the general U.S. population. Acad Med 2014;89(3):443-51.

3. Bacchi S, Licinio J. Qualitative literature review of the prevalence of depression in medical students compared to students in non-medical degrees. Acad Psychiatry 2015;39:293-9.

4. Brenneisen Mayer F, Souza Santos I, Silveira PS, et al. Factors associated to depression and anxiety in medical students: A multicenter study. BMC Med Educ 2016;16(1): 282.

5. Panova T, Carbonell $X$. Is Smartphone addiction really an addiction? J Behav Addict 2018;7(2):252-9.

6. Cheever NA, Rosen LD, Carrier LM, et al. Out of sight is not out of mind: The impact of restricting wireless mobile device use on anxiety levels among low, moderate and high users. Computers in Human Behavior 2014;37:290-7.

7. Clayton RB, Leshner G, Almond A. The extended iSelf: the impact of iPhone separation on cognition, emotion, and physiology. J Computer-Mediated Communication 2015;20:119-35

8. Diagnostic and statistical manual of mental disorders, 5th ed Washington, DC: American Psychiatric Association, 2013.

9. Aljomaa SS, Mohammad MF, Albursan IS, et al. Smartphone addiction among university students in the light of some variable. Computers in Human Behavior 2016;6:155-64.

10. Demirci K, Akgonul M, Akpinar A. Relationship of smartphone use severity with sleep quality, depression, and anxiety in university students. J Behav Addict 2015;4(2):85-92.

11. Andreassen CS, Pallesen S, Griffiths MD. The relationship between addictive use of social media, narcissism, and selfesteem: Findings from a large national survey. Addict Behav 2017;64:287-93.

12. Lin $\mathrm{CY}$, Imani V, Griffiths MD, et al. Temporal associations between morningness/eveningness, problematic social media use, psychological distress, and daytime sleepiness: Mediated roles of sleep quality and insomnia. J Sleep Res 2020;00:e13076.

13. Chen $\mathrm{H}$, Pakpour $A H$, Leung $H$, et al. Comparing generalized and specific problematic smartphone/internet use: Longitudinal relationships between smartphone application-based addiction and social media addiction and psychological distress. J Behav Addict 2020;9(2):410-9.

14. Wong HY, Mo HY, Potenza MN, et al. Relationships between severity of internet gaming disorder, severity of problematic social media use, sleep quality and psychological distress. Int J Environ Res Public Health 2020;17(6):1879.

15. Alimoradi Z, Lin CY, Imani V, et al. Social media addiction and sexual dysfunction among Iranian women: The mediating role of intimacy and social support. J Behav Addict 2019;8(2):318-25.

16. Alimoradi Z, Lin CY, Broström A, et al. Internet addiction and sleep disorders: A systematic review and meta-analysis. Sleep Med Rev 2019;47:51-61.

17. El Hangouche AJ, Jniene A, Aboudrar S, et al. Relationship 
between poor quality sleep, excessive daytime sleepiness and low academic performance in medical students. Adv Med Educ Pract 2018;9:631-8.

18. Dendle C, Baulch J, Pellicano R, et al. Medical student psychological distress and academic performance. Med Teach 2018;40(12):1257-63.

19. Azizi SM, Soroush A, Khatony A. The relationship between social networking addiction and academic performance in Iranian students of medical sciences: A cross-sectional study. BMC Psychol 2019;7(1):28.

20. Javaeed A, Jeelani $R$, Gulab $S$, et al. Relationship between internet addiction and academic performance of undergraduate medical students of Azad Kashmir. Pak J Med Sci 2020;36(2):229-33.

21. Ibrahim NK, Baharoon BS, Banjar WF, et al. Mobile phone addiction and its relationship to sleep quality and academic achievement of medical students at King Abdulaziz University, Jeddah, Saudi Arabia. J Res Health Sci 2018;18(3):e00420.

22. Buysse DJ, Reynolds CF, Monk TH, et al. The Pittsburgh Sleep Quality Index: A new instrument for psychiatric practice and research. Psychiatry Res 1989;28(2):193-213.

23. Agargun MY, Kara $H$, Anlar $O$. Validity and reliability of Pittsburgh Sleep Quality Index (Turkish). Turk Psikiyatri Derg 1996;7:107-11.

24. Sahin C, Yagcı M. Social media addiction scale-adult form: Validity and reliability study (Turkish). Journal of Ahi Evran University Kırşehir Faculty of Education (KEFAD) 2017;18(1):523-38.

25. Kwon M, Lee JY, Won WY, et al. Development and validation of a smartphone addiction scale (SAS). PLoS One 2013;8(2):e56936.

26. Demirci K, Orhan $H$, Demirdas A, et al. Validity and reliability of the Turkish Version of the Smartphone Addiction Scale in a younger population. Bulletin of Clinical Psychopharmacology 2014;24(3):226-34.

27. Abu-Snieneh HM, Aroury AMA, Alsharari AF, et al. Relationship between sleep quality, using social media platforms, and academic performance among university students. Perspect Psychiatr Care 2020;56(2):415-23.

28. Hashmi AM, Naz S, Ali AA, et al. Smart phones and medical students: Pleasant distraction or dangerous addiction? JPMA 2019;69(12):1891-5.
29. Al Suwayri SM. The impact of social media volume and addiction on medical student sleep quality and academic performance: A cross-sectional observational study. Imam J Appl Sci 2016; 1(2):80-7.

30. Van der Heijden KB, Vermeulen MCM, Donjacour CEHM, et al. Chronic sleep reduction is associated with academic achievement and study concentration in higher education students. J Sleep Res 2018;27(2):165-74.

31. Ahrberg K, Dresler M, Niedermaier S, et al. The interaction between sleep quality and academic performance. J Psychiatr Res 2012;46:1618-22.

32. Baert S, Omey E, Verhaest D, et al. Mister Sandman, bring me good marks! On the relationship between sleep quality and academic achievement. Soc Sci Med 2015;130:91-8.

33. Genzel L, Ahrberg K, Roselli C, et al . Sleep timing is more important than sleep length or quality for medical school performance. Chronobiol Int 2013;30:766-71.

34. Lemma S, Berhane Y, Worku A, et al. Good quality sleep is associated with better academic performance among university students in Ethiopia. Sleep Breath 2014;18:25763.

35. Medeiros ALD, Mendes DB, Patricia FL, et al. The relationships between sleep-wake cycle and academic performance in medical students. Biol Rhythm Res 2001;32: 263-70.

36. Lim J, Dinges DF. A meta-analysis of the impact of shortterm sleep deprivation on cognitive variables. Psychol Bull 2010;136:375-89.

37. Jiang $X L$, Zheng $X Y$, Yang J, et al. A systematic review of studies on the prevalence of insomnia in university students. Public Health 2015;129:1579-84.

38. Mohammadbeigi A, Absari R, Valizadeh F, et al. Sleep quality in medical students; The impact of over-use of mobile cellphone and social networks. J Res Health Sci 2016;16(1):46-50. 